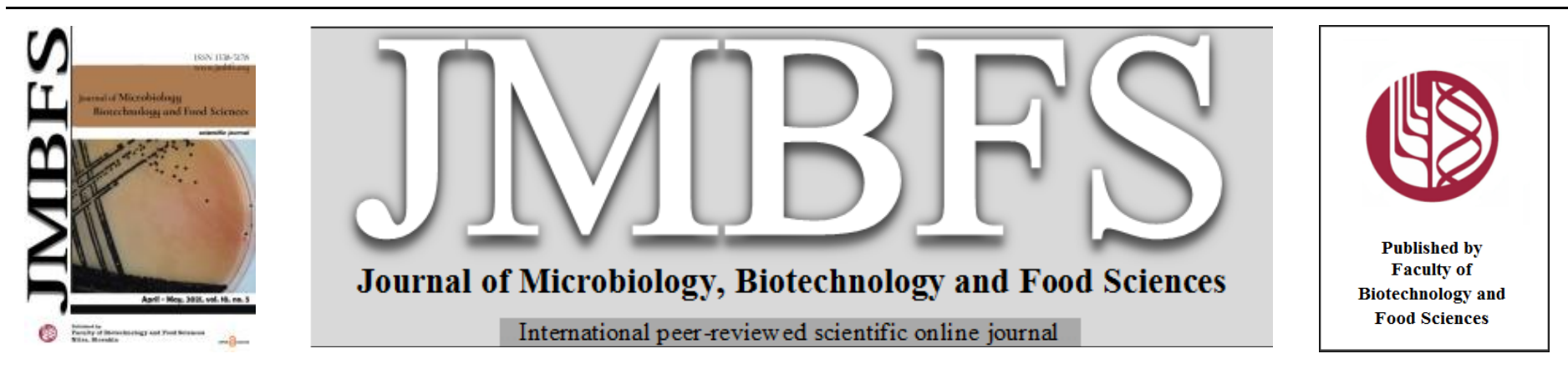

\title{
IDENTIFICATION OF LIPOPEPTIDES PRODUCED BY BACILLUS AMYLOLIQUEFACIENS STRAINS
}

\author{
Zdenka Bedlovičová* $*^{1}$, Karolína Englerová ${ }^{2}$, Radomíra Nemcová ${ }^{2}$, Miroslava Kačániová ${ }^{3}$
}

Address(es): RNDr. Zdenka Bedlovičová, PhD.,

${ }^{1}$ University of VEterinary Medicine and Pharmacy, Department of Chemistry, Biochemistry and Biophysics, Komenského 73,04181 Košice, Slovakia, +421 944219 817

${ }^{2}$ University of Veterinary Medicine and Pharmacy, Department of Microbiology and Immunology, Komenského 73, 04181 Košice, Slovakia.

${ }^{3}$ Department of Fruit sciences, Viticulture and Enology, Faculty of Horticulture and Landscape Engineering, Slovak University of Agriculture, Tr. A. Hlinku 2, 94976

Nitra, Slovakia, Department of Bioenergy and Food Technology, Faculty of Biology and Agriculture, University of Rzeszow, Zelwerowicza St. 4, 35601 Rzeszow, Poland.

*Corresponding author: zdenka.bedlovicova@uvlf.sk

https://doi.org/10.15414/jmbfs.3690

ARTICLE INFO

Received 8. 9. 2020

Revised 10. 11. 2020

Accepted 11. 11. 2020

Published 1. 4. 2021

Short communication

open 2 access

\section{ABSTRACT}

In this study we isolated and identified the lipopeptides produced by Bacillus amyloliquefaciens strains 1/6k and 4/9, which were isolated from Adriatic Sea. Lipopeptides belong to the family of cyclic biosurfactants representing a group of surface active compounds produced by various microorganisms. Studied Bacillus spp. strains were able to produce cyclic lipopeptides surfactin, iturin A and fengycin. The characterisation of lipopeptides was studied by various analytical techniques (high-performance liquid chromatography HPLC and matrix-assisted laser desorption/ionization time-of-flight analysis for molecular mass determination - MALDI-TOF/MS). These methods confirmed co-production of three lipopeptides - surfactin, iturin A and fengycin by Bacillus amyloliquefaciens.

Keywords: Bacillus, lipopeptides, HPLC, MALDI-TOF/MS

\section{INTRODUCTION}

Surfactants are defined as surface active agents with attractive properties and can be produced by chemical or biological way (Al-araji et al., 2007). Surfactants produced by biological synthesis are biosurfactants (BSs) and can be generated by various species of microorganisms (bacteria, fungi and yeasts) (Akbari $\boldsymbol{e t}$ al. 2018). BSs offer a variety of advantages over the chemical surfactants, $e . g$ better biodegradation, bioavailability, biocompatibility, stability and low toxicity for the environment (Hentati et al., 2019; Mulligan, 2005). Biosurfactants are able to reduce the surface tension of liquids, gases and solids, and thus enable their mixing in the form of emulsions in liquids (Cappello et al., 2012). These facts lead to use of biosurfactants in the fields of food, cosmetic, agriculture, petrochemistry, medicine and pharmacy as antibacterial and antifungal compounds (Banat et al., 2014; Roy, 2017).

Chemically, the biosurfactants can be divided into glycolipids, lipopeptides, phospholipids, fatty acids or neutral lipids (Roy, 2017). A common feature of all the mentioned types of compounds is their composition from the lipophilic (hydrocarbon chain of fatty acid or steroid ring) and hydrophilic (carboxylic group of fatty or amino acids, hydroxyl group of saccharides, eventually, the phosphoryl group of phospholipids) moieties (Kim et al., 2004).

Surfactins, fengycins and iturins are the mostly known types of lipopeptide biosurfactants. Surfactin and fengycin contain a cyclic lactone ring consisting of $\beta$-hydroxy fatty acid containing 14 or 15 carbons and heptapeptide (surfactin) and decapeptide (fengycin) with various amino acids (Bonmatin et al., 1995; Sun et al., 2006), iturin forms a lactam ring with $\beta$-amino acid attached to heptapeptide (Volpon et al., 2007). The fatty acid chain of iturin A lipopeptide varies from 13 to 17 carbon atoms (Delcambe et al., 1977). All the mentioned types of lipopeptide biosurfactants exhibit many important biological activities due to the growing problem of resistance of conventional antibiotics, for example antimicrobial properties, on the other hand indicate also antiviral, antifungal or cytolytic activity (Kim et al., 2004; Meena \& Kanwar, 2015).

The aim of this study was to investigate several methods including TLC, HPLC and MALDI-TOF/MS for detection of biosurfactant metabolites produced by $B$. amyloliquefaciens strains.

\section{MATERIAL AND METHODS}

\section{Lipopeptide biosurfactants isolation}

Bacillus amyloliquefaciens 1/6k, and 4/9 strains were isolated from marine water, sand, and seaweed obtained from the Adriatic Sea as we presented in our previous study (Englerová et al., 2019). Biosurfactants (BSs) were isolated using a modified method by Plaza (Plaza, et al., 2015). $300 \mathrm{~mL}$ aliquot of McKeen medium was inoculated by a night culture of Bacillus amyloliquefaciens strains The medium was then cultivated for $72 \mathrm{~h}$ at $27^{\circ} \mathrm{C}$, and $140 \mathrm{rpm}$ (Shaker SKO-D XL, ARGOlab, Capri, Italy). After cultivation, the appropriate bacterial culture was centrifuged $\left(4754 \mathrm{~g} / 65 \mathrm{~min} / 4^{\circ} \mathrm{C}\right)$ and the supernatant was acidified by $6 \mathrm{M}$ hydrochloric acid to $\mathrm{pH} 2$. During the night the precipitation was formed at $4{ }^{\circ} \mathrm{C}$, and then it was centrifuged again $\left(4754 \mathrm{~g} / 55 \mathrm{~min} / 4^{\circ} \mathrm{C}\right)$. The sediment was dissolved in $100 \mathrm{~mL}$ of distilled water. The $\mathrm{pH}$ of the samples was adjusted to the value of 7 by adding of $1 \mathrm{M} \mathrm{NaOH}$. Lipopeptides were extracted to the organic phase consisting of ethyl acetate and methanol in 4:1 $(v / v)$ ratio. The organic layers were combined and dried by sodium sulphate, filtered off, and the solvent was evaporated (IKA RV 10 Digital, Germany). The yellow oil product was then lyophilized and stored at $-20^{\circ} \mathrm{C}$.

\section{Thin-layer chromatography}

Thin-layer chromatography analysis of the extracted lipopeptide biosurfactants was performed using ethyl acetate as the eluent. A $20 \mu \mathrm{L}$ aliquot of the product was applied to a silica gel TLC plate (TLC Silica gel $60 \mathrm{~F}_{254}$, Merck, Darmstadt, Germany). After development of the chromatogram and evaporation of the eluent, the plate was visualized using $0.5 \%$ ninhydrin solution in $n$-butanol with $1 \mathrm{~mL}$ of acetic acid addition as the developing agent for the detection of amino groups of peptides.

\section{High performance liquid chromatography}

The isolated BSs mixtures were dissolved in acetonitrile and filtered through a $0.22 \mu \mathrm{m}$ membrane filter. A $20 \mu \mathrm{L}$ volume was injected onto a reverse-phase column YMC MeteoricCore C18 Bio $(150 \times 4.6 \mathrm{~mm})$ with particle size of $2.7 \mu \mathrm{L}$ (YMC Co., Ltd., Japan). The analysis was carried out using a Dionex UltiMate 3000 UHPLC system equipped with a Chromeleon Chromatography Data 
System, version 7.2 (Thermo Fisher Scientific, Braunschweig, Germany) using photodiode array detector (DAD). The analyses were performed at the wavelength of $214 \mathrm{~nm}$. The $0.5 \mathrm{mg} \cdot \mathrm{mL}^{-1}$ concentrations of standards surfactin, fengycin and iturin A (all purchased from Sigma Aldrich, Germany) were used. The mobile phases consisted of $0.05 \%$ trifluoroacetic acid (TFA, Merck, Germany) in acetonitrile (Sigma Aldrih, Germany) (eluent A) and $0.05 \%$ TFA in water (eluent B). Optimization of the separation strategy was done stepwise using a gradient elution focused on the mobile phases flow, ratio and time of analysis. The final gradient strategy for the acetonitrile-water mobile phase system was as follows: $0-5 \mathrm{~min} 100 \% \mathrm{~B}$ with flow rate of $0.5 \mathrm{~mL} \cdot \mathrm{min}^{-1} ; 5-10 \mathrm{~min}$ linear gradient from $0 \%$ to $10 \%$ of eluent A with flow rate of $0.8 \mathrm{~mL} \cdot \mathrm{min}^{-1}$; and $10-$ 75 min linear gradient from $10 \%$ to $90 \%$ of eluent A with $1.5 \mathrm{~mL} \cdot \mathrm{min}^{-1}$ flow rate.

\section{MALDI-TOF/MS analysis}

HPLC purified isoforms were analyzed by a matrix-assisted lase desorption/ionization time-of-flight analysis (MALDI-ToF MS Biotyper, Bruker Daltonics, Germany) for molecular mass determination. One microlitre of the sample was applied to a target plate (Bruker Daltonics, Germany, MSP Target) and allowed to dry at room temperature. The matrix used for co-crystallization was 2- $\alpha$-cyano-4-hydroxycinnamic acid, HCCA (Sigma, USA. The UV laser $(337 \mathrm{~nm})$ was used for desorption and ionization and the voltage of $20 \mathrm{kV}$. The mass spectra were acquired using a Microflex LT mass spectrometer with the flexControl 3.0 software (Bruker Daltonics, Germany). M/z values were measured in the range from 800 to 2,000 . Spectra were measured randomly by 100 laser shots. For analysis a flexAnalysis 3.0 software (Bruker Daltonics, Germany) was used. Detection of peaks was done by Centroid detection algorithm with a signal-to-noise threshold of 1 , relative intensity threshold of 0 $\%$, minimum threshold of 0 , and a peak width of $0.2 \mathrm{~m} / \mathrm{z}$.

\section{RESULTS AND DISCUSSION}

\section{Thin-layer chromatography}

The chemical characterization of BSs isolated from Bacillus amyloliquefaciens strains $1 / 6 \mathrm{k}$, and $4 / 9$ was firstly performed by TLC. The TLC analysis suggested that the produced BSs were peptides as they developed colour change (purple spots were observed) when ninhydrin was used for visualisation.

\section{High-performance liquid chromatography}

Optimized conditions for the reverse phase HPLC method with UV/Vis detection were developed for direct detection of iturin A, fengycin and surfactin (Figure 1a). Relevant parameters for HPLC analysis were varied, such as the flow rate and ratio of solvents used as mobile phase. Finally, the $0.05 \%$ of trifluoroacetic acid in acetonitrile and water was utilized as a mobile phase. For the examined sample, three main groups of peaks were observed in the HPLC chromatogram of lipopeptides from studied strains of $B$. amyloliquefaciens spp., as shown in figure $1 \mathrm{~b}$ and $1 \mathrm{c}$. The retention time from $11.25-22.5 \mathrm{~min}$ was attributed to iturin $\mathrm{A}$ standard, followed by peaks of fengycin $(35.0-45.0 \mathrm{~min})$, and for surfactin there were observed three peaks at $15.73 ; 18.46$ and $20.90 \mathrm{~min}$ and the group of peaks eluted in the range of $51.0-60.0 \mathrm{~min}$.

As shown in Figure 1b, the HPLC chromatogram of the studied LPs from $B$. amyloliquefaciens strain 4/9, contained components of surfactin and fengycin, the most common families of LPs. The peaks of fengycin and surfactin isomers could be attributed by the retention times to standards of the mentioned LPs. The retention times for iturin A standard isomers were observed at 11.79, 12.18, $13.37,14.47,15.13,15.90,16.14$, and $16.21 \mathrm{~min}$, while in the $B$ amyloliquefaciens 1/6k (Figure 1c) strain the retention times observed for iturin A were $11.78,13.13,14.01,15.01$, and $16.16 \mathrm{~min}$. In the sample obtained from $B$. amyloliquefaciens $4 / 9$ no iturin A peaks were observed in HPLC chromatograms. The retention times for surfactin standard isomers were 15.73, $18.46,21.93 \mathrm{~min}$ and the group of peaks including $51.44,53.98,54.43,54.55$ $55.96,56.12$, and $56.23 \mathrm{~min}$. In the $4 / 9$ strain there were detected peaks of surfactin at 21.72, 51.04, 53.94, 54.54, 55.05, 55.63, 56.08, and 56.26 min Surfactin isoforms peaks were observed at 14.92, 47.62, 50.75, 50.99, 51.81, $52.81,54.51,55.02,55.59,56.08$, and $56.26 \mathrm{~min}$. for B. amyloliquefaciens $1 / 6 \mathrm{k}$ strain. The retention times for fengycin standard isomers, were $36.43,37.49$, $38.42,39.64,40.19,40.79,40.97$, and $42.31 \mathrm{~min}$ while in the $4 / 9$ bacterial strain there were noticed peaks of fengycin at $36.59,37.23,40.67,41.64$, and 42.34 min. and for strain $1 / 6 \mathrm{k}$ at $36.40,37.23,38.34,39.28,40.11,40.71,41.04$, and $42.30 \mathrm{~min}$. These results allowed us to conclude that B. amyloliquefaciens $4 / 9$ and 1/6k may produce the LPs surfactin, iturin A and fengycin. This confirms the results of the genetic study mentioned in previous work (Englerová et al., 2019).

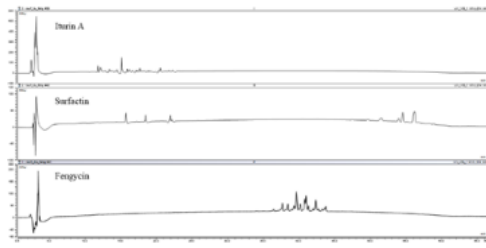

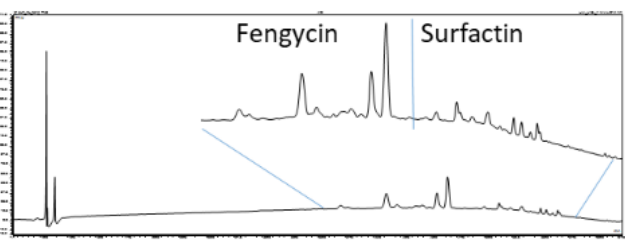

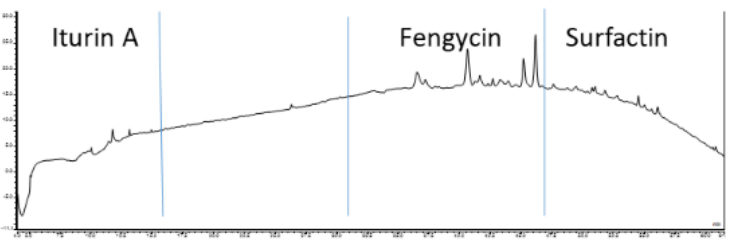

Figure 1 HPLC chromatograms of lipopeptides: a) standards of iturin A, fengycin, and surfactin; b) obtained from B. amyloliquefaciens 4/9 strain; c) obtained from B. amyloliquefaciens $1 / 6 \mathrm{k}$ strain

Lipopeptides isolated using extraction method from the isolates $B$ amyloliquefaciens $4 / 9$, and $1 / 6 \mathrm{k}$ were further characterised by HPLC and MALDI-TOF/MS analysis. Several papers showed the possibility of using HPLC methods for characterization of BSs (Ashraf et al., 2016; Hentati et al., 2019; Kim et al., 2010; Kim et al., 2004; Plaza et al., 2015; Sarwar et al., 2018). For example, Yang and his colleagues (Yang et al., 2015) developed a three-stage gradient elution strategy for acetonitrile-water mobile phase with a flow rate of $0.8 \mathrm{~mL} / \mathrm{min}$. The total time of analysis was $25 \mathrm{~min}$. Our analysis performed under the mentioned conditions was unsuccessful, as the LPs were not separated, so we decided to modify this method. The first step was to change the mobile phase by adding TFA, which was also used by some authors (Gong et al., 2015; Mubarak

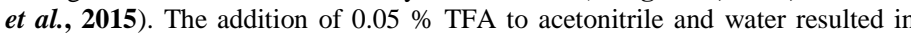
better separation of the studied LPs in the samples. By using our gradient elution strategy, iturin A, fengycin and surfactin isoforms were separated within the retention times of $11-17$ minutes for iturin A, 36-43 minutes for fengycin and 51 - 57 minutes for surfactin isoforms. To summarize, we can conclude that under the conditions used, we were able to separate successfully LPs from $B$ amyloliquefaciens $4 / 9$, and $1 / 6 \mathrm{k}$, and in the future we plan to apply this method for identification of lipopeptide BSs isolated from other Bacillus spp.

\section{MALDI-TOF/MS analysis}

LP-producing $B$. amyloliquefaciens $4 / 9$, and $1 / 6 \mathrm{k}$ was grown under preestablished conditions in the McKeen medium and its extract was obtained by ethyl acetate/methanol $(4: 1, v / v)$ extraction. The lyophilized extract was then subjected to MALDI-TOF/MS analysis as an acetonitrile solution. In the spectra of isolated LPs there were detected peaks having masses very similar to LP compounds.

As shown in Figure 2, the most intensive signals in the $m / z$ range of $1400-1600$ were observed in the MALDI-TOF/MS spectra of the isolated LP mixture. The peak at $\mathrm{m} / z=887.9$ was attributed to iturin A, peaks at $\mathrm{m} / \mathrm{z}=1029$ and 1044 to surfactin and the ions between $\mathrm{m} / z=1400-1600$ were regarded as belonging to fengycin $(1479.7,1465.5,1451.5,1437.1,1423)$. These results confirmed that $B$ amyloliquefaciens 4/9 (Figure 2a) produces surfactin, fengycin and iturin A, while the strain 1/6k (Figure 2b) only surfactin and fengycin, the families of lipopeptide BSs. 


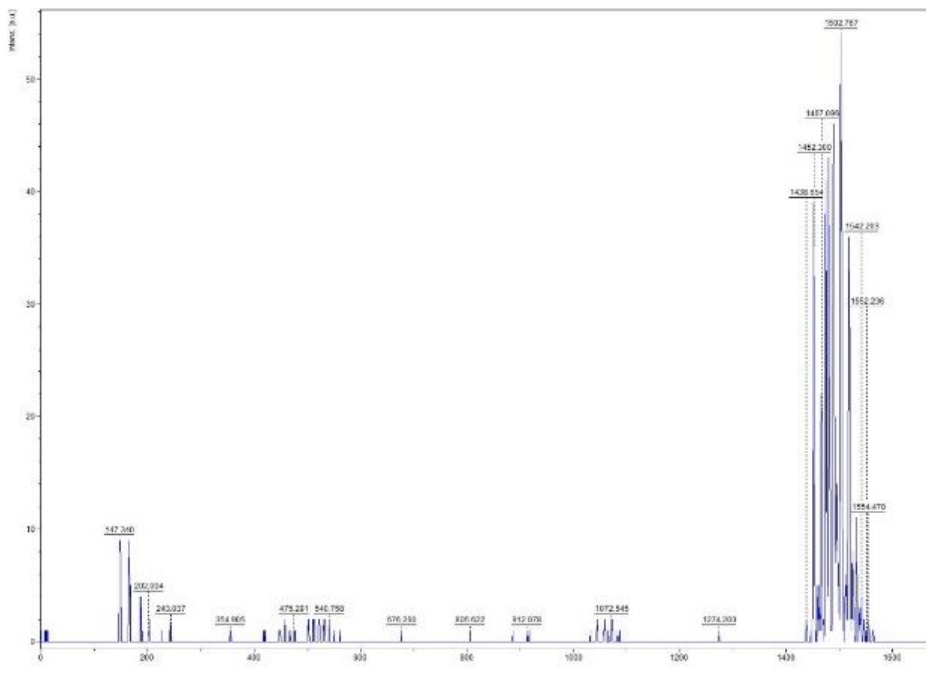

a

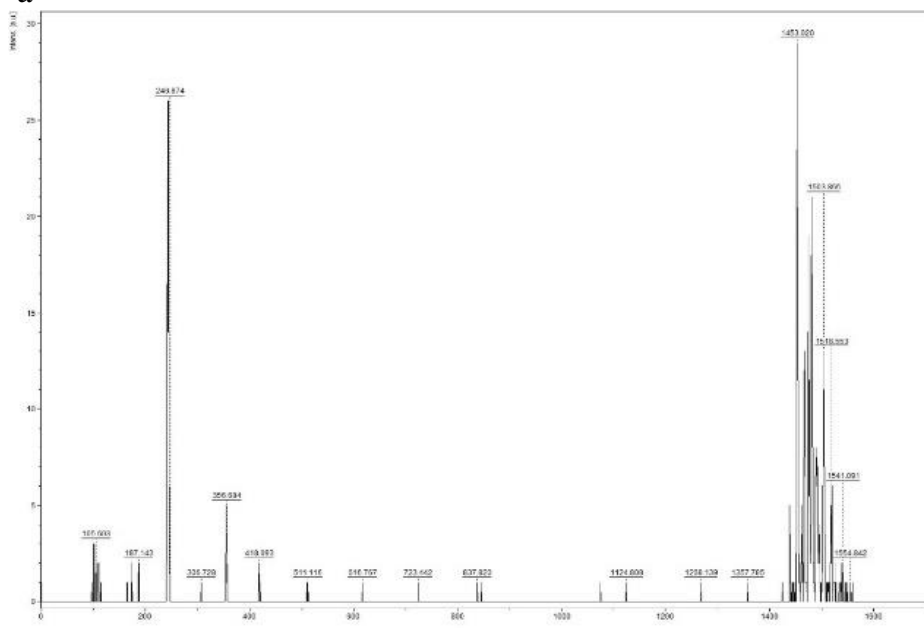

b

Figure 2 MALDI-TOF/MS spectra of lipopeptides: a) obtained from $B$ amyloliquefaciens $4 / 9$ strain; b) obtained from B. amyloliquefaciens $1 / 6 \mathrm{k}$ strain

MALDI-TOF/MS analysis is a method broadly used for identification of cyclic LPs. This method affords high sensitivity and exhibits sequence ions of the cyclic peptides (Yang et al., 2015). For identification of LPs from B. amyloliquefaciens $4 / 9$, and $1 / 6 \mathrm{k}$ we detected ions at $\mathrm{m} / \mathrm{z}=1093.9$ (attributed to iturin A), 1016.4, 1029 and 1044 (surfactin) and 1465.5 (fengycin). Our results are in line with the available literature, for example the study of B. subtilis CMB32 strain by Kim $\boldsymbol{e}$ al. (2010), in which they analysed the structures of LPs. The authors observed several peaks in the range of 1016 and 1044 attributed to surfactin class, then the peaks in the range of 1452 and 1542 for fengycin group and between 1066 and 1094 they observed iturin class peaks. A similar mass intensity was described in the study by Bernat et al. (2016), who used the MALDI-TOF/TOF method.

\section{CONCLUSION}

Studying microbes able to produce bioactive compounds is a promising approach to the management of infectious diseases. Our study demonstrated that Bacillus spp. isolated from the Adriatic Sea are good candidates for isolation of BSs. The isolates demonstrated responsibility for production of surfactin, fengycin and iturin, the three main lipopeptide families. Afterwards, LPs were successfully isolated from B. amyloliquefaciens $4 / 9$, and $1 / 6 \mathrm{k}$. Results obtained by HPLC and MALDI-TOF/MS analyses confirmed co-production of surfactin, iturin A and fengycin by mentioned isolates. The antimicrobial and antibiofilm activities of isolated LPs require further investigation.

Acknowledgments: This study was supported by the project VEGA 1/0081/17.

\section{REFERENCES}

Akbari, S., Abdurahman, N. H., Yunus, R. M., Fayaz, F., \& Alara, O. R. (2018) Biosurfactants - a new frontier for social and environmental safety: a mini review. Biotechnology Research and Innovation, 2(1), 81-90. https://doi.org/10.1016/j.biori.2018.09.001

Al-araji, L., Noor, R., Raja, Z., \& Rahman, A. (2007). Microbial Surfactant. Asia Pacific Journal of Molecular Biology and Biotechnology, 15(3), 99-105.

Ashraf, J. M., Ansari, M. A., Khan, H. M., Alzohairy, M. A., \& Choi, I. (2016).
Green synthesis of silver nanoparticles and characterization of their inhibitory effects on AGEs formation using biophysical techniques. Scientific Reports, 6 20414. https://doi.org/10.1038/srep20414

Banat, I. M., Satpute, S. K., Cameotra, S. S., Patil, R., \& Nyayanit, N. V. (2014) Cost effective technologies and renewable substrates for biosurfactants' production. Frontiers in Microbiology, 5, 1-18. https://doi.org/10.3389/fmicb.2014.00697

Bernat, P., Paraszkiewicz, K., Siewiera, P., Moryl, M., Płaza, G., \& Chojniak, J. (2016). Lipid composition in a strain of Bacillus subtilis, a producer of iturin A lipopeptides that are active against uropathogenic bacteria. World Journal of Microbiology and Biotechnology, 32(10). https://doi.org/10.1007/s11274-0162126-0

Bonmatin, J.-M., Labbé, H., Grangemard, I., Peypoux, F., Maget-Dana, R., Ptak, M., \& Michel, G. (1995). Production, isolation and characterization of [Leu4] [Ile4] surfactins from Bacillus subtilis. Letters in Peptide Science, 2(1), 41-47. https://doi.org/10.1007/bf00122922

Cappello, S., Genovese, M., Della Torre, C., Crisari, A., Hassanshahian, M. Santisi, S., ... \& Yakimov, M. M. (2012). Effect of bioemulsificant exopolysaccharide (EPS2003) on microbial community dynamics during assays of oil spill bioremediation: A microcosm study. Marine Pollution Bulletin, 64(12), 2820-2828. https://doi.org/10.1016/j.marpolbul.2012.07.046

Delcambe, L., Peypoux, F., Besson, F., Gisnaud, M., \& Michel, G. (1977). Structure of Iturin and Iturin-like Substances. Biochemical Society Transactions, 5(4), 1122-1124. https://doi.org/https://doi.org/10.1042/bst0051122

Englerová, K., Nemcová, R., Bedlovičová, Z., Mad’ar, M., Styková, E., \& Király, J. (2019). Bacillus spp. capable to produce the Biosurfactants as bioactive Compounds. In A. Slavica, R. Terapić, A. L. Pavunc, \& D. Kifer (Eds.), Power of Microbes in Industry and Environment 2019, Sveti Martin na Muri, Croatia (p. 115).

Gong, A. D., Li, H. P., Yuan, Q. S., Song, X. S., Yao, W., He, W. J., ... \& Liao, Y. C. (2015). Antagonistic mechanism of iturin a and plipastatin a from Bacillus amyloliquefaciens S76-3 from wheat spikes against Fusarium graminearum. PLOS ONE, 1O(2), 1-18. https://doi.org/10.1371/journal.pone.0116871

Hentati, D., Chebbi, A., Hadrich, F., Frikha, I., Rabanal, F., Sayadi, S., ... \& Chamkha, M. (2019). Production, characterization and biotechnological potential of lipopeptide biosurfactants from a novel marine Bacillus stratosphericus strain FLU5. Ecotoxicology and Environmental Safety, 167, 441-449. https://doi.org/10.1016/j.ecoenv.2018.10.036

Kim, P. Il, Ryu, J., Kim, Y. H., \& Chi, Y. T. (2010). Production of biosurfactant lipopeptides iturin A, fengycin, and surfactin A from Bacillus subtilis CMB32 for control of Colletotrichum gloeosporioides. Journal of Microbiology and Biotechnology, 20(1), 138-145. https://doi.org/10.4014/.jmb.0905.05007

Kim, P. I., Bai, H., Bai, D., Chae, H., Chung, S., Kim, Y., ... \& Chi, Y. T. (2004). Purification and characterization of a lipopeptide produced by Bacillus thuringiensis CMB26. Journal of Applied Microbiology, 97(5), 942-949. https://doi.org/10.1111/j.1365-2672.2004.02356.x

Meena, K. R., \& Kanwar, S. S. (2015). Lipopeptides as the Antifungal and Antibacterial Agents: Applications in Food Safety and Therapeutics. BioMed Research International, 2015, 1-9. https://doi.org/10.1155/2015/473050

Mubarak, M. Q. E., Hassan, A. R., Hamid, A. A., Khalil, S., \& Isa, M. H. M. (2015). A simple and effective isocratic HPLC method for fast identification and quantification of surfactin. Sains Malaysiana, 44(1), 115-120. https://doi.org/10.17576/jsm-2015-4401-16

Mulligan, C. N. (2005). Environmental applications for biosurfactants, 133, 183 198. https://doi.org/10.1016/j.envpol.2004.06.009

Plaza, G., Chojniak, J., Rudnicka, K., Paraszkiewicz, K., \& Bernat, P. (2015). Detection of biosurfactants in Bacillus species: Genes and products identification. Journal of Applied Microbiology, 119(4), 1023-1034 https://doi.org/10.1111/jam.12893

Roy, A. (2017). A Review on the Biosurfactants: Properties, Types and its Applications. Journal of Fundamentals of Renewable Energy and Applications, $8(1), 1-5$. https://doi.org/10.4172/20904541.1000248

Sarwar, A., Brader, G., Corretto, E., Aleti, G., Abaidullah, M., Sessitsch, A., \& Hafeez, F. Y. (2018). Qualitative analysis of biosurfactants from Bacillus species exhibiting antifungal activity. PLoS ONE, 13(6), 1-15. https://doi.org/10.1371/journal.pone.0198107

Sun, L., Lu, Z., Bie, X., Lu, F., \& Yang, S. (2006). Isolation and characterization of a co-producer of fengycins and surfactins, endophytic Bacillus amyloliquefaciens ES-2, from Scutellaria baicalensis Georgi. World Journal of $\begin{array}{llll}\text { Microbiology and } \quad \text { Biotechnology, 22, 1259-1266 } & \text { 22, }\end{array}$ https://doi.org/10.1007/s11274-006-9170-0

Volpon, L., Tsan, P., Majer, Z., \& Vass, E. (2007). NMR structure determination of a synthetic analogue of bacillomycin Lc reveals the strategic role of 1 -Asn1 in the natural iturinic antibiotics, 67, 1374-1381. https://doi.org/10.1016/j.saa.2006.10.027

Yang, H., Li, X., Li, X., Yu, H., \& Shen, Z. (2015). Identification of lipopeptide isoforms by MALDI-TOF-MS/MS based on the simultaneous purification of iturin, fengycin, and surfactin by RP-HPLC. https://doi.org/10.1007/s00216015-8486-8 